\title{
C-H activation by immobilized heterogeneous photocatalysts
}

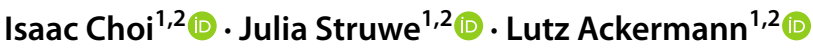

Received: 21 September 2021 / Accepted: 1 November 2021 / Published online: 16 November 2021

(c) The Author(s) 2021

\begin{abstract}
During the last decades, the merger of photocatalysis with transition metal chemistry has been surfaced as a sustainable tool in modern molecular syntheses. This Account highlights major advances in synergistic photo-enabled $\mathrm{C}-\mathrm{H}$ activations. Inspired by our homogenous ruthenium- and copper-catalyzed $\mathrm{C}-\mathrm{H}$ activations in the absence of an exogenous photosensitizer, this Account describes the recent progress on heterogeneous photo-induced $\mathrm{C}-\mathrm{H}$ activation enabled by immobilized hybrid catalysts until September 2021, with a topical focus on recyclability as well as robustness of the heterogeneous photocatalyst.
\end{abstract}

\section{Introduction}

The tremendous progress achieved in molecular syntheses during the last decade has resulted in a significant improvement of the organic chemistry. Thus, modern organic synthesis is the key to the development of structural complexity, including the transformation of hydrocarbons to useful and high-valued compounds by straightforward and sustainable methods. While the development of metal-catalyzed crosscoupling reactions had resulted in significant advances [1, 2], major drawbacks continued to limit this approach, such as the pre-functionalization of starting materials and stoichiometric waste production. In stark contrast, the direct activation of omnipresent $\mathrm{C}-\mathrm{H}$ bonds emerged as a transformative tool $[3,4]$ for the step-economical and sustainable approach [5-7] not only towards organic chemistry, but indeed also applied areas, such as drug discovery, crop protection, and materials science (Fig. 1a) [8-11].

Photocatalysis has recently been identified as an increasingly powerful technique in sustainable organic syntheses. In 2007, a pioneering report by Osawa [12], merging photocatalysis with transition metal-catalyzed reactions (Fig. 1b), unlocked a dormant area of photocatalysis [13, 14]. In sharp

Lutz Ackermann

Lutz.Ackermann@chemie.uni-goettingen.de

1 Institut für Organische und Biomolekulare Chemie, Georg-August-Universität Göttingen, Tammannstraße 2, 37077 Göttingen, Germany

2 Wöhler Research Institute for Sustainable Chemistry (WISCh), Georg-August-Universität Göttingen, Tammanstraße 2, 37077 Göttingen, Germany contrast, Ackermann [15-17] and later Greaney [18, 19] elegantly disclosed $\mathrm{C}-\mathrm{H}$ activation by ruthenaphotoredox catalysis under exogenous-photosensitizer-free conditions. While $\mathrm{C}-\mathrm{H}$ activation has predominantly exploited noble $4 \mathrm{~d}$ or $5 \mathrm{~d}$ transition metals, the introduction of Earth-abundant and cost-effective $3 \mathrm{~d}$ metal catalysts [20-23], particularly copper and cobalt, allows for more sustainable and photoinduced $\mathrm{C}-\mathrm{H}$ activation. In this context, Ackermann reported the first photo-induced copper-catalyzed $\mathrm{C}-\mathrm{H}$ arylation and $\mathrm{C}-\mathrm{H}$ chalcogenation of heterocycles in the absence of additional photocatalysts [24, 25]. Subsequently, Rueping and Sundararaju disclosed an elegant cobalt-catalyzed alkyne annulation with the aid of $\mathrm{Na}_{2}$ Eosin $\mathrm{Y}$ photosensitizer under visible light irradiation [26].

In spite of this considerable progress, photo-induced organometallic $\mathrm{C}-\mathrm{H}$ activation was thus far largely limited to soluble catalysts. Homogeneous catalysis is generally considered to be inadequate for the reuse of catalysts and often leads to undesired trace-metal impurities in the target products. In stark contrast, heterogeneous catalysis allows for the recovery of the catalyst, which increases recyclability as well as reusability in $\mathrm{C}-\mathrm{H}$ activation [27]. In addition, the concept of immobilized catalysts has recently been recognized for thermal direct transformations, with a focus on heterogenized noble metals, such as palladium-, rhodium-, and iridium-catalyzed thermal transformations [28-32]. Unlike classical heterogeneous catalysts, immobilized heterogeneous catalysts consist of an inorganic support and a homogeneous catalyst, which is covalently anchored by an organic linker. Thus, these immobilized catalysts provide an avenue for tailorable and recyclable catalysis. Indeed, the heterogenized 


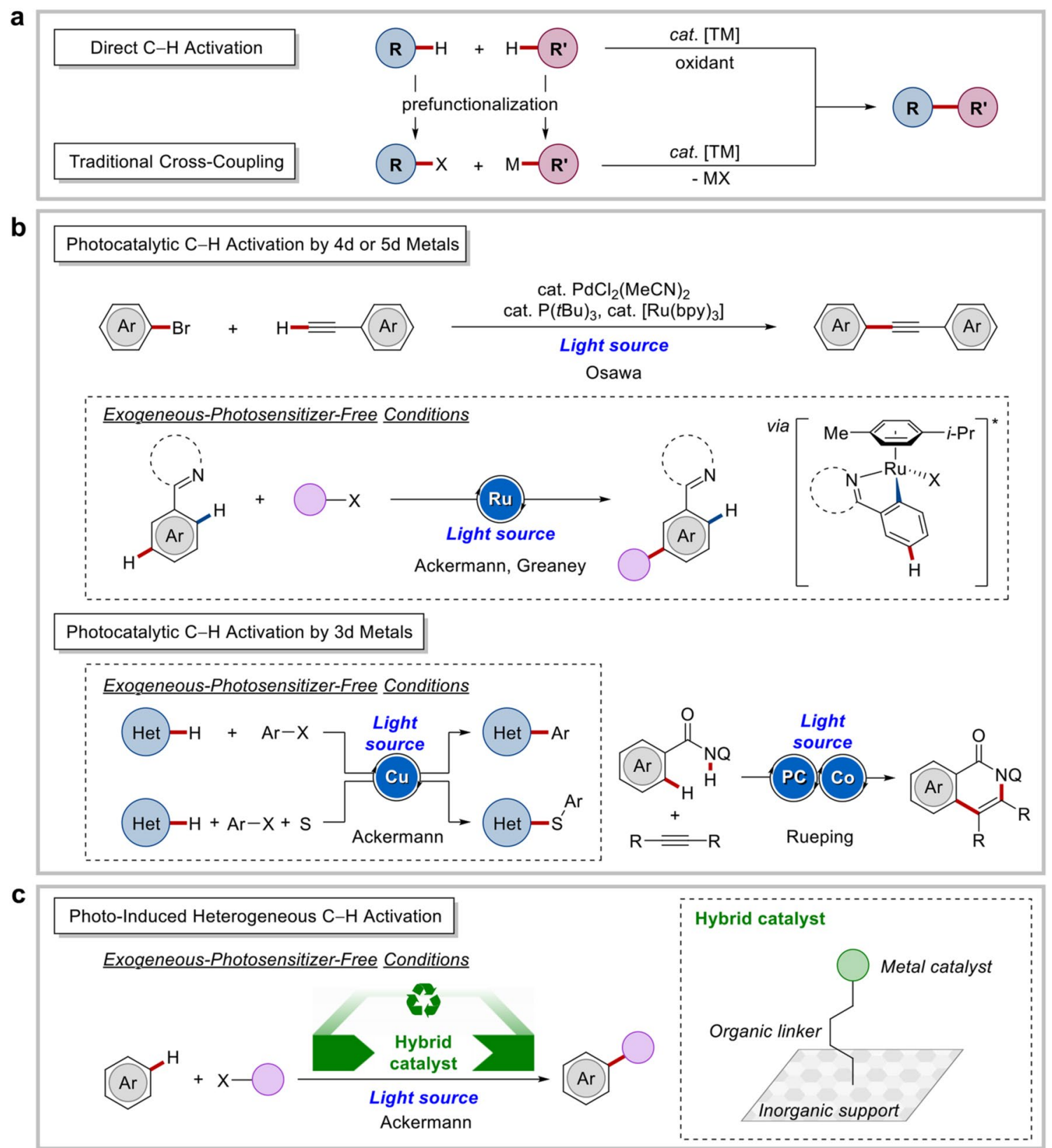

Fig. 1 Photo-induced heterogeneous $\mathrm{C}-\mathrm{H}$ activation without exogenous photocatalysts. a Conventional cross-coupling reactions and direct $\mathrm{C}-\mathrm{H}$ activation. b Homogeneous photo-induced $\mathrm{C}-\mathrm{H}$ activation. $\mathbf{c}$ Heterogeneous photocatalytic approach in $\mathrm{C}-\mathrm{H}$ activation

homogeneous catalysts-often referred to as hybrid catalysts - have been very recently utilized for photocatalytic $\mathrm{C}-\mathrm{H}$ activation (Fig. 1c), which will be discussed within this Account.

Since the detailed aspects of homogeneous and heterogeneous metal-catalyzed $\mathrm{C}-\mathrm{H}$ activation have previously been reviewed [4, 5, 22, 27], the scope of this Account includes photo-induced organometallic $\mathrm{C}-\mathrm{H}$ activation by means of recyclable, covalently bound metal catalysts under exogenous-photocatalyst-free conditions until September 2021, excluding outer-sphere $\mathrm{C}-\mathrm{H}$ functionalization processes.

\section{Photo-induced distal C-H activation by heterogeneous ruthenium catalyst}

While a wealth of ortho-selective $\mathrm{C}-\mathrm{H}$ activations of arenes has been reported, methods for remote meta- or para-selective $\mathrm{C}-\mathrm{H}$ functionalizations remain underdeveloped. Hence, only few strategies have thus far been realized for distal functionalizations by the use of expensive iridium and palladium catalysts [33-35]. In sharp contrast, meta-C-H functionalizations have been realized by ruthenium catalysis. The ruthenium-catalyzed 
meta-C-H functionalization was observed by Ackermann (Fig. 2) in 2011 during studies on ortho-selective alkylation of phenyl pyridine $\mathbf{1}$ using carboxylate assistance [36]. This reaction proceeds trough initial cyclometalation and ligand exchange generating complex 6 [37]. Subsequent single-electron-transfer (SET) with alkyl halide 2 yields ruthenium(III) species 7, which then delivers intermediate 9 . Subsequent rearomatization and protodemetalation delivers the meta-substituted product $\mathbf{4}$, and regenerates the active catalyst. Afterward, numerous studies for distal $\mathrm{C}-\mathrm{H}$ functionalizations by ruthenium catalysis have subsequently been reported [38-41]. Here, computational studies, such as Fukui radical indices [42, 43] or molecular orbital analysis [44], unraveled key mechanistic insights into ruthenium-catalyzed meta-C-H functionalizations.

Recently, the group of Ackermann disclosed photoinduced remote meta-C-H functionalization under exogenous-photosensitizer-free conditions (Fig. 3) [16]. In this strategy, the cyclometalated ruthenium complex 14 which generated from the substrate $\mathbf{1 1}$ is excited by visible light irradiation, giving intermediate $\mathbf{1 5}$, which is followed by SET to the alkyl halide $\mathbf{1 2}$. Thereby, ruthenium complex 16 and alkyl radical 17 are generated. Next, the alkyl radical 17 attacks the aromatic moiety at the position para to ruthenium, forming intermediate $\mathbf{1 8}$, which undergoes intramolecular SET and subsequent rearomatization to provide ruthenacycle 20. Thereafter, a protodemetalation process affords the desired meta-functionalized arene 13. In the photo-induced conditions, elevated reaction temperatures can be avoided for distal $\mathrm{C}-\mathrm{H}$ activation.

Inspired by their previous studies, in 2020 , the group of Ackermann introduced the polymer-based immobilized ruthenium catalyst $\mathbf{2 3}$ for site-selective photo-induced $\mathrm{C}-\mathrm{H}$ activation of arenes $\mathbf{2 1}$ under exceedingly mild reaction conditions, affording meta-functionalized arenes $\mathbf{2 4}$ (Fig. 4) [45]. Based on detailed mechanistic insights [42, 43], an immobilized phosphine was identified as being optimal for effective meta-C-H alkylations [45]. It is noteworthy that biomass-derived 2-MeTHF was identified to be the optimal reaction medium [46], while additional exogenous photocatalysts were not required for this distal transformation. In this study, various heteroarenes, such as pyridine, purine, and oxazoline, efficiently afforded meta-decorated arenes 24a-c and the heterogenized ruthenium catalyst $\mathbf{2 3}$ was found to be reusable for the photo-induced meta-C-H alkylation.

The established hybrid ruthenium catalysis was also applicable to thermal reaction conditions (Fig. 5). Thereby, the heterogenized ruthenium catalyst $\mathbf{2 3}$ featured excellent
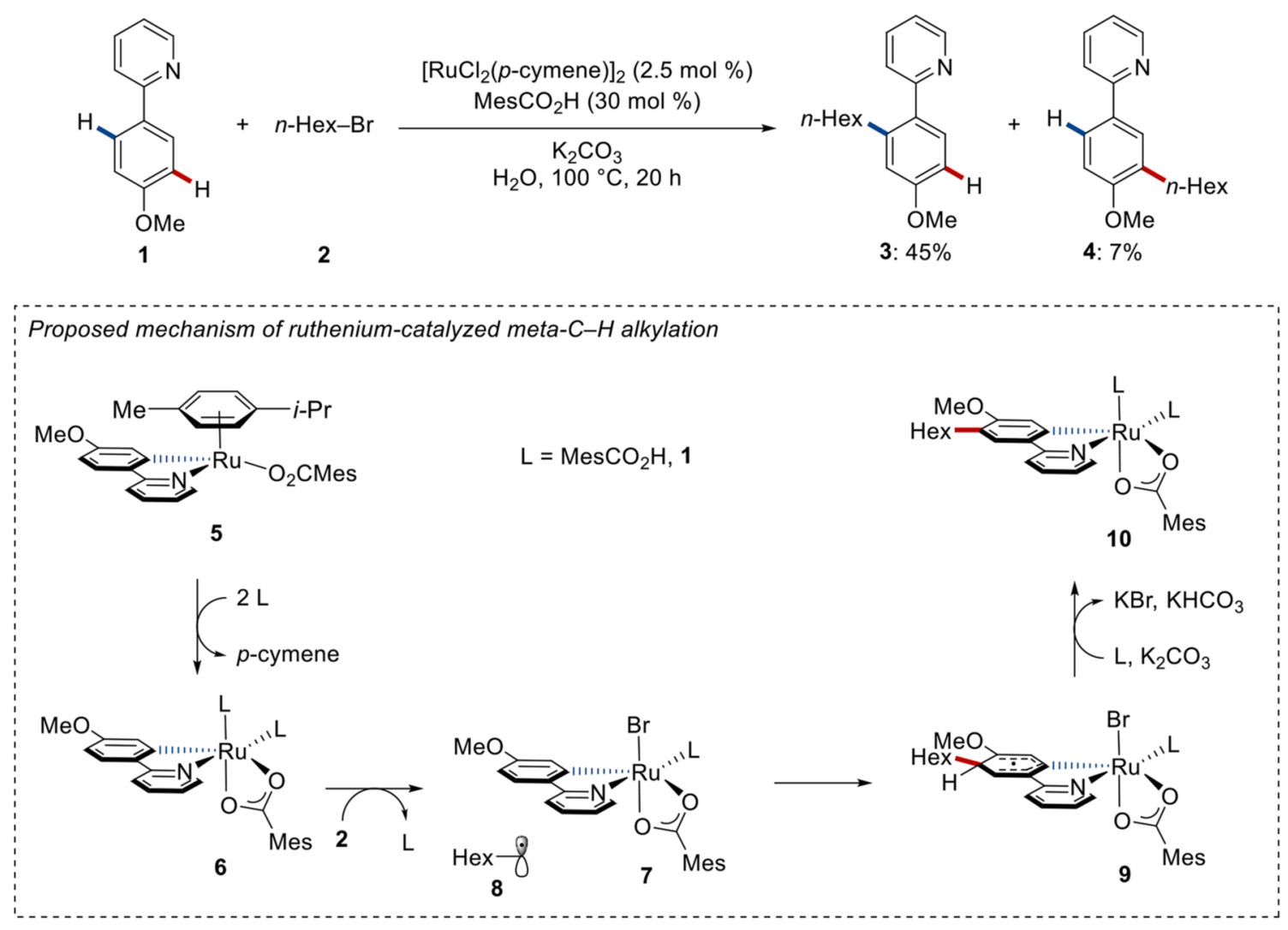

$\mathrm{L}=\mathrm{MesCO}_{2} \mathrm{H}, 1$

3: $45 \%$

4: $7 \%$

Fig. 2 The first observation of remote meta-C-H functionalization 

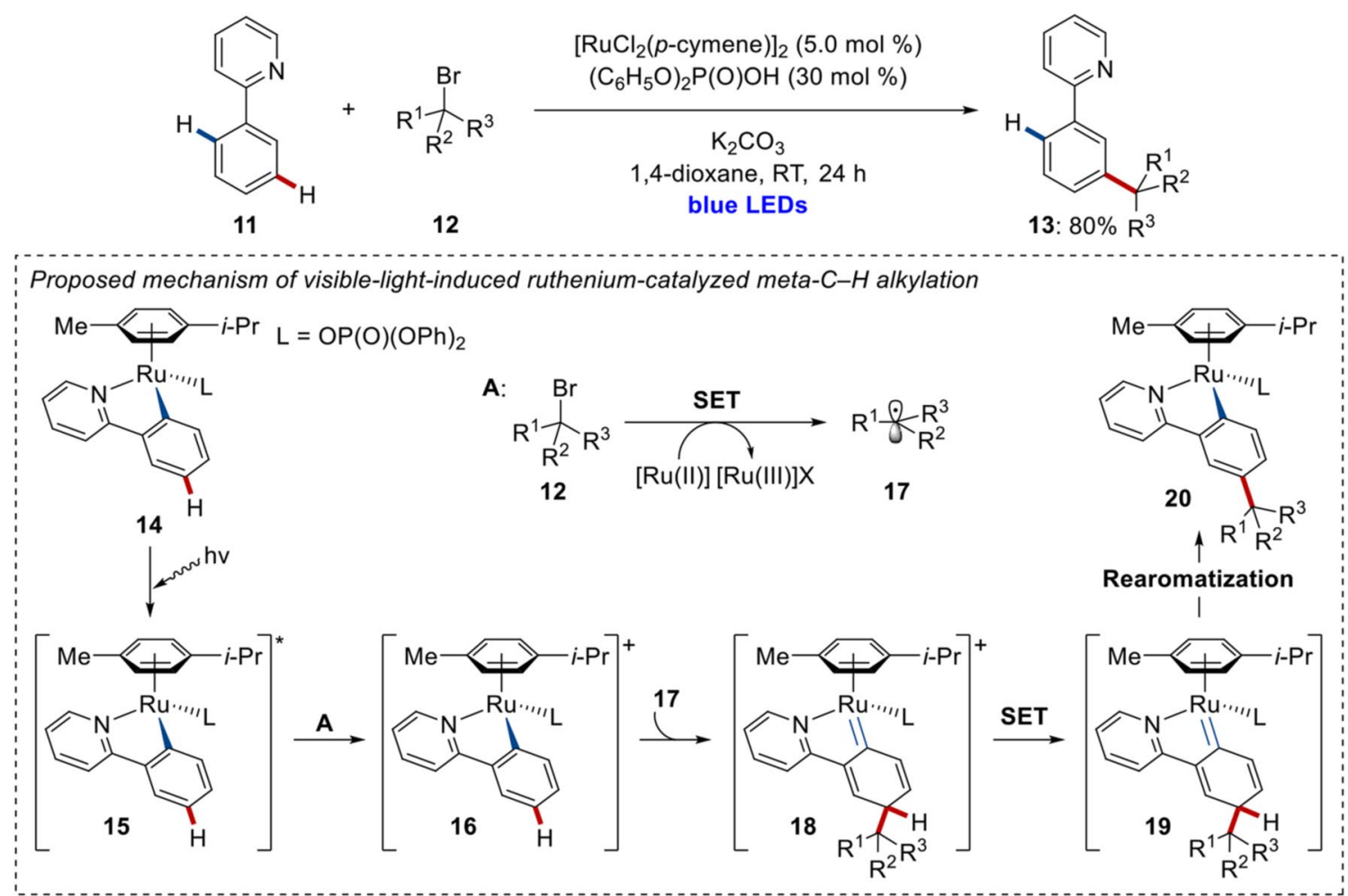

Fig. 3 Visible-light-induced ruthenium-catalyzed meta-C-H alkylation

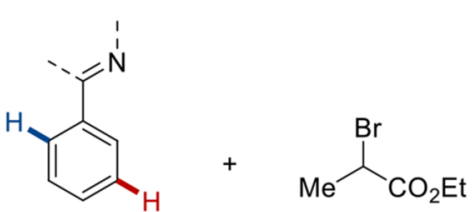

21

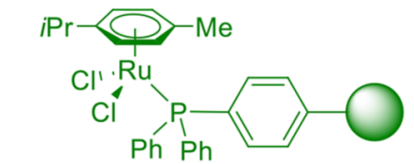

$23(10 \mathrm{~mol} \%)$

KOAc, $\mathrm{H}_{2} \mathrm{O}, 2-\mathrm{MeTHF}$

RT, $24 \mathrm{~h}, \mathrm{~N}_{2}$

Blue LEDs

O Polystyrene

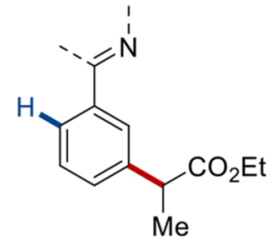

24
-<smiles>CCOC(=O)C(C)c1ccccc1-c1ccccn1</smiles>

$24 a$

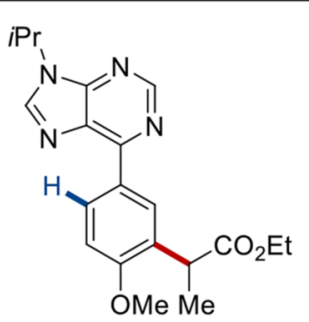

24b<smiles>CCOC(=O)C(C)c1cc(C2=NCCO2)c(OC)cc1OC</smiles>

24c

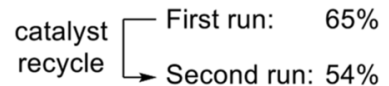

catalyst - First run: $\quad 62 \%$

recycle $\longrightarrow$ Second run: $48 \%$

Fig. 4 Photo-induced meta-C-H alkylation by recyclable hybrid ruthenium catalyst 
Fig. 5 Highly reusable hybrid ruthenium catalyst for distal $\mathrm{C}-\mathrm{H}$ functionalization

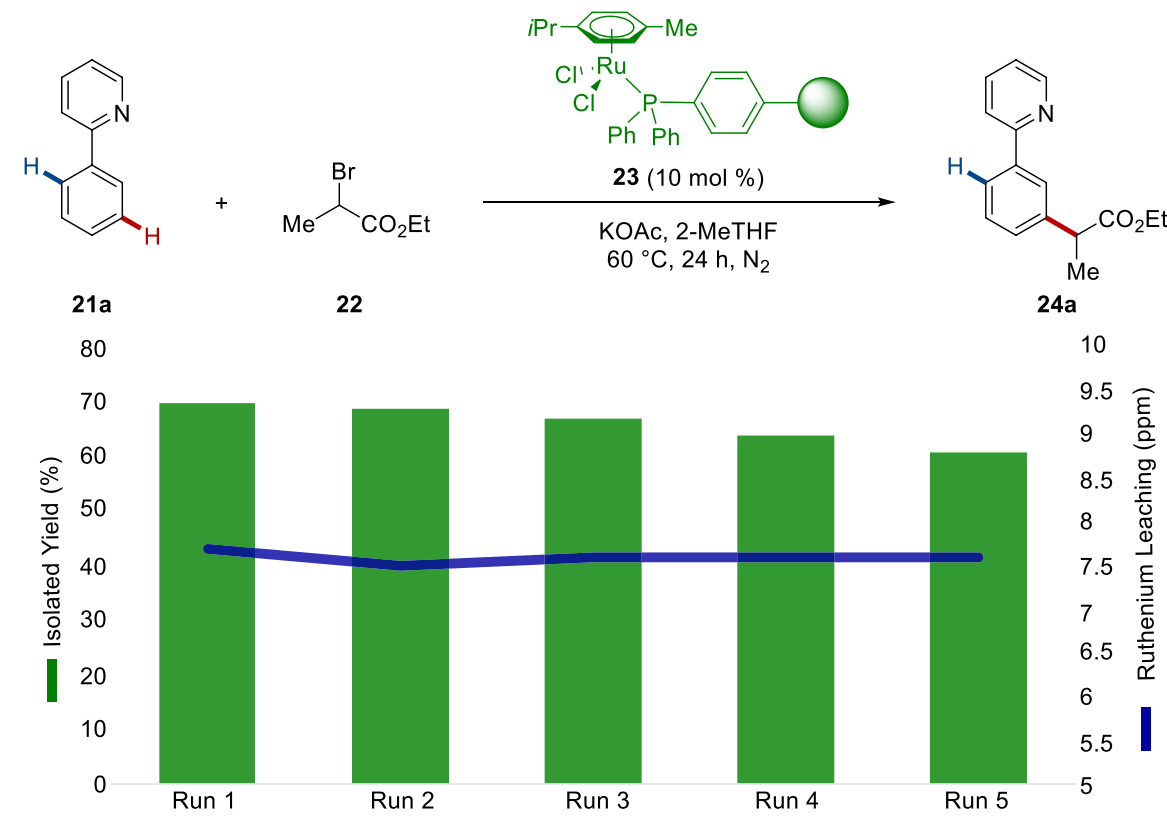

recyclability without significant loss of catalytic efficacy, enabling versatile access to meta-C-H alkylated arene $\mathbf{2 4 a}$. Importantly, less than $8 \mathrm{ppm}$ of ruthenium was detected by detailed inductively coupled plasma-optical emission spectrometry (ICP-OES) studies of the reaction mixture, reflecting negligible leaching of the transition metal. Notably, the heterogeneity of the covalently bound ruthenium catalyst 23 was verified by hot-filtration, poison, and three-phase tests, while the spectroscopic and microscopic characterization of the catalyst, along with detailed experimental and computational mechanistic studies, provided strong support for high position-selectivity enabled by the reusable hybrid catalyst $\mathbf{2 3}$.

\section{Photo-induced heterogeneous copper-catalyzed C-H activation}

Copper complexes are easily accessible and versatile $3 \mathrm{~d}$ metal catalysts for molecular assembly, because of copper's natural abundance, low toxicity, and wide range of oxidation states. Thus, copper catalysts have largely been exploited for new bond formation, such as $\mathrm{C}-\mathrm{C}$ or $\mathrm{C}-$ heteroatom bonds [47-49]. In contrast to early examples of copper-catalyzed $\mathrm{C}-\mathrm{H}$ functionalizations through SET mechanisms, copper has in recent years emerged as a viable metal for $\mathrm{C}-\mathrm{H}$ activation through organometallic $\mathrm{C}-\mathrm{Cu}$ intermediates [50-55]. Particularly, copper-catalyzed $\mathrm{C}-\mathrm{H}$ arylations have been extensively investigated with notable contributions by Daugulis [56], Miura [57], and Ackermann [58].

Despite these major advances, copper-catalyzed $\mathrm{C}-\mathrm{H}$ activation with aryl halides were largely restricted by their harsh reaction conditions with reaction temperatures commonly ranging from 120 to $160^{\circ} \mathrm{C}$. However, the emergence of photocatalysis allowed for various sustainable organic syntheses under mild conditions, which further enabled photo-induced copper-catalyzed C-H activation. In 2016, the Ackermann group thus disclosed the first photo-induced copper-catalyzed $\mathrm{C}-\mathrm{H}$ arylations of heterocycles $\mathbf{2 5}$ under exceedingly mild reaction conditions, providing C2-arylated benzothiazoles 27 (Fig. 6a) [24]. Here, abundant and inexpensive copper iodide allowed for the direct arylation of azoles under UV- or blue-light-irradiation. This photocatalytic $\mathrm{C}-\mathrm{H}$ activation manifold proved later amenable to the copper-catalyzed C-H chalcogenation of heterocycles $\mathbf{2 5}$ with elemental sulfur and selenium, affording the chalcogenated products 28 or 29 (Fig. 6b) [25].

Encouraged by our reports, Ackermann and coworkers developed a novel heterogenized copper catalyst 31, enabling the immobilization of copper iodide onto the bipyridyl group containing SBA-15 silica support 30 (Fig. 7) [59]. The chelating $N, N$-coordination motif is frequently found in homogenous $\mathrm{C}-\mathrm{H}$ arylation copper catalysts [22].

This silica-based hybrid copper catalyst $\mathbf{3 1}$ was exploited for $\mathrm{C}-\mathrm{H}$ arylation of azoles ( 32 and $\mathbf{3 3}$ ) with ample substrate scope (Fig. 8a). Interestingly, the sole use of copper iodide fell short in efficiently delivering the desired arylated product 34a, while the developed reaction protocols provided an easy and sustainable access to the alkaloid texamine (35d) with high levels of site selectivity at the $\mathrm{C} 2$ position. Indeed, the broadly applicable covalently bound copper photocatalysis was extended to feature $N$-methyl benzimidazole $\mathbf{3 6}$ as a viable substrate under slightly modified reaction conditions, significantly 


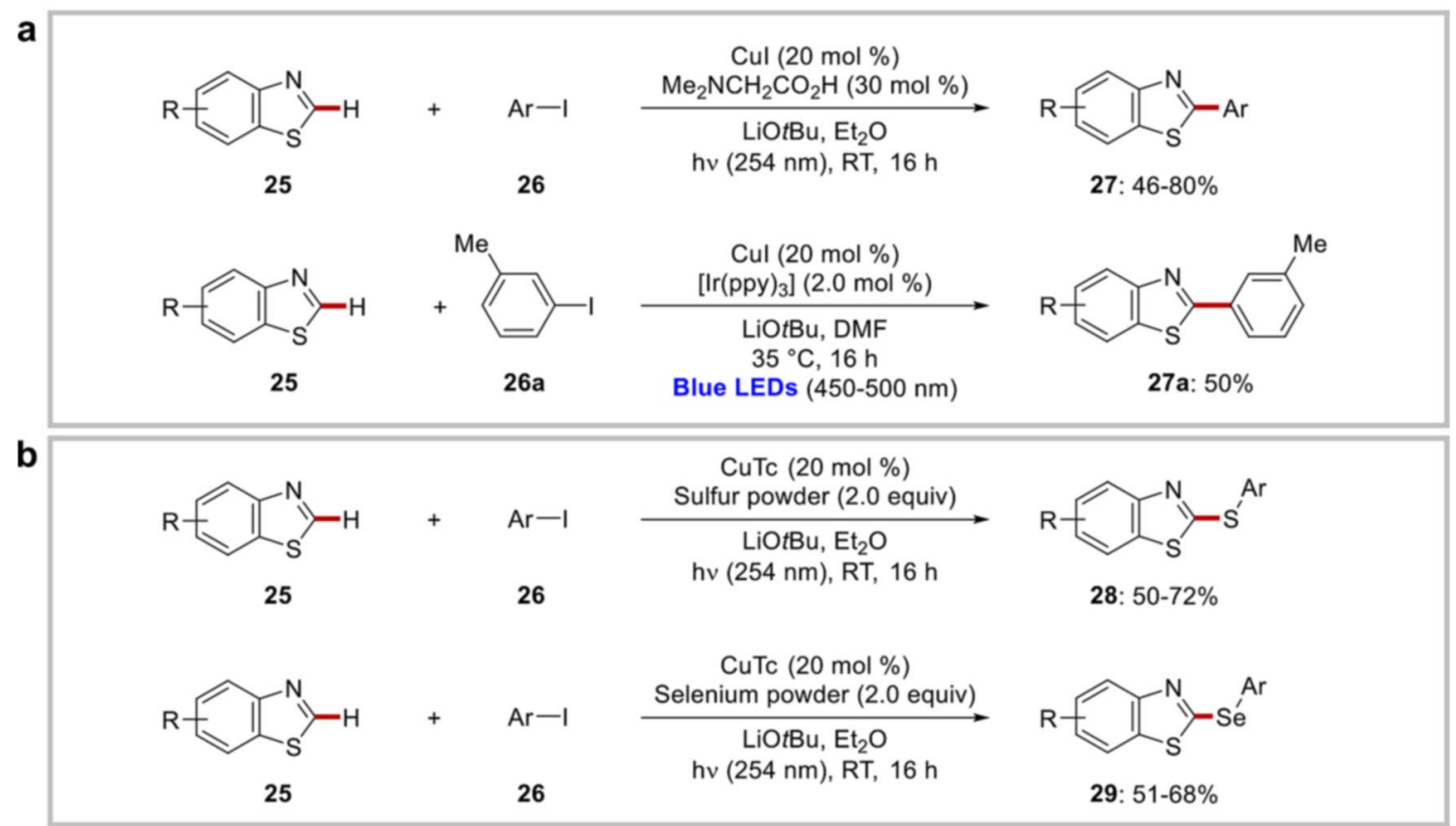

Fig. 6 The emergence of photo-induced copper-catalyzed $\mathrm{C}-\mathrm{H}$ activation. a $\mathrm{C}-\mathrm{H}$ arylations by cupraphotocatalysis. b Copper-catalyzed photocatalytic $\mathrm{C}-\mathrm{H}$ chalcogenations

Fig. 7 Preparation of hybrid copper catalyst

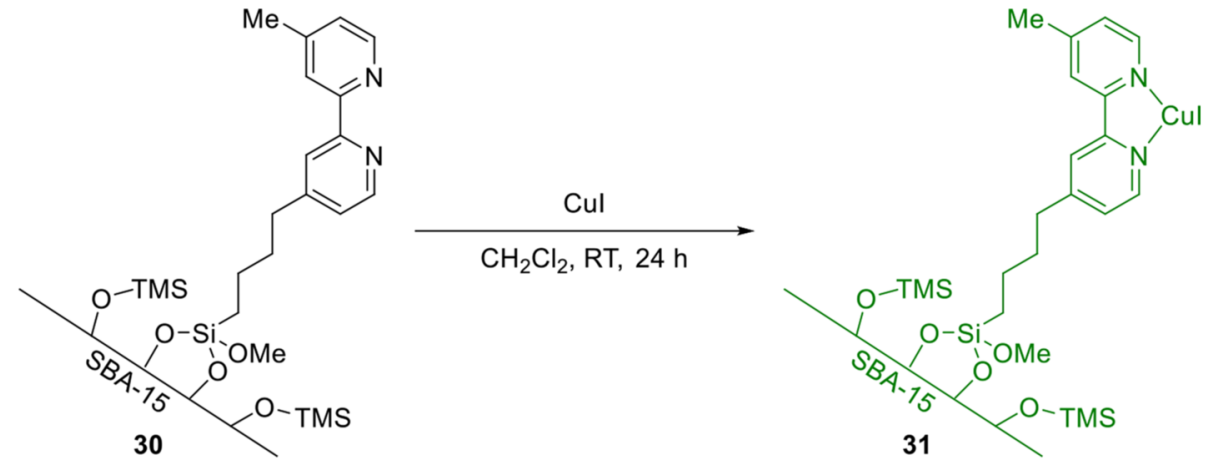

widening the functional group tolerance to include sensitive ketones and esters (Fig. 8b). More importantly, costeffective aryl bromides $\mathbf{4 0}$ were also identified as suitable substrates, reflecting the robustness of hybrid copper catalysis in photochemical C-H activation (Fig. 8c).

It is particularly noteworthy that the immobilized copper catalyst $\mathbf{3 1}$ was indeed recyclable, as shown by the reuse tests, along with careful ICP-OES analysis (Fig. 9). Furthermore, while detailed heterogeneity studies highlighted the heterogeneous nature of the heterogeneous copper catalyst $\mathbf{3 1}$ in the photo-induced $\mathrm{C}-\mathrm{H}$ activation, analysis by high-resolution transmission electron microscopy (HRTEM) and X-ray photoelectron spectroscopy (XPS) indicated the outstanding robustness and stability of the novel immobilized copper catalyst 31 .

\section{Summary and outlook}

During the last decades, photocatalysis has undergone renaissance, and photochemical reactions have been identified as an increasingly viable toolbox in molecular sciences. Thus, photocatalysis for $\mathrm{C}-\mathrm{H}$ activation has surfaced as a sustainable platform in modern synthesis, allowing for innovative chemical transformations. In sharp contrast, photocatalytic $\mathrm{C}-\mathrm{H}$ activations using a tailorable heterogeneous catalysts have until recently proven elusive. Herein, we have described our recent progress in photoinduced $\mathrm{C}-\mathrm{H}$ activation by recyclable covalently bound metal catalysts. First, a polymer-based hybrid ruthenium catalyst enabled photocatalytic distal meta-C-H alkylation 


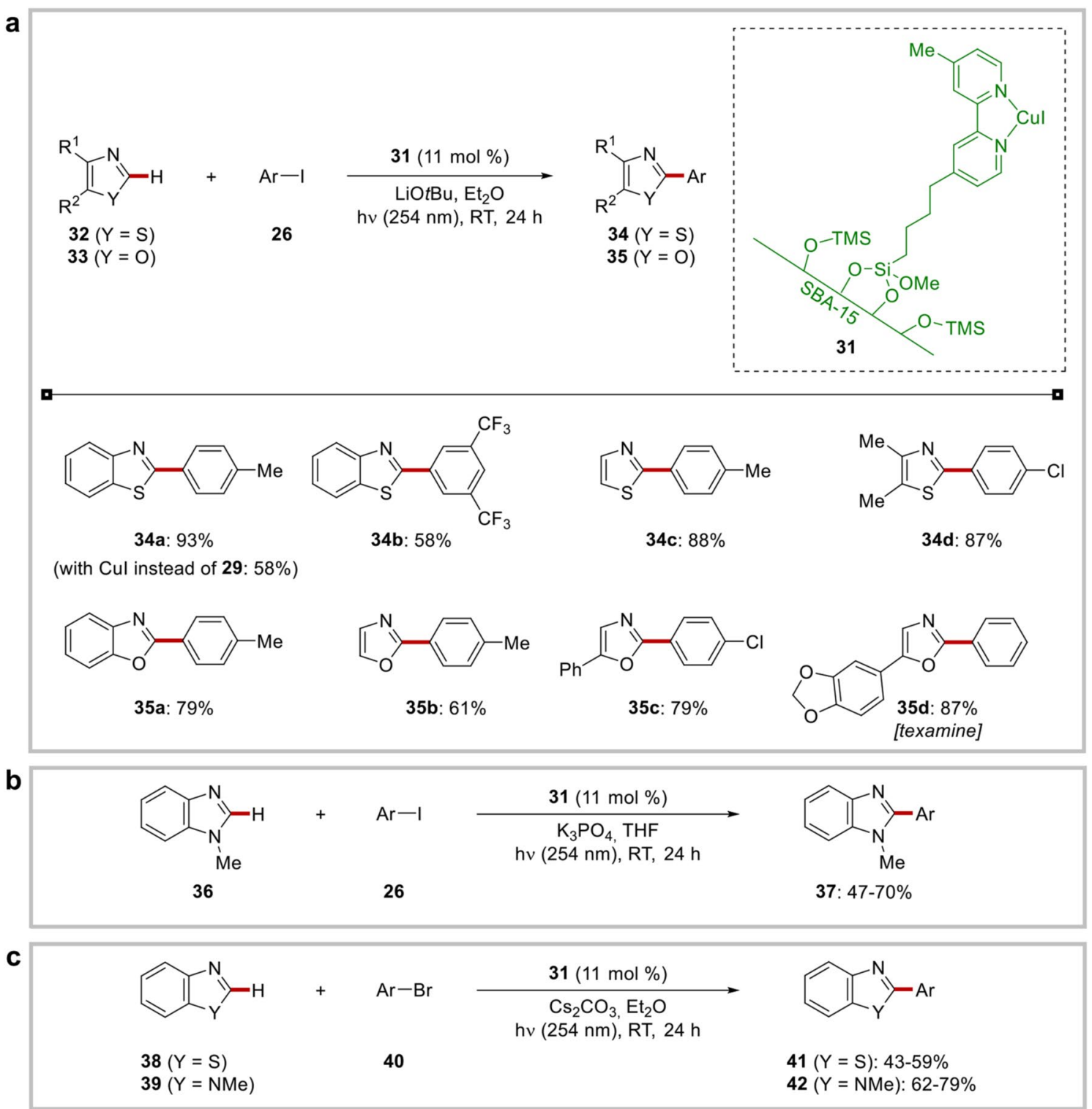

Fig. 8 Photo-induced heterogeneous copper catalysis for $\mathrm{C}-\mathrm{H}$ arylations. a Photocatalytic $\mathrm{C}-\mathrm{H}$ activation by a versatile immobilized copper catalyst. b Hybrid copper catalysis enabling photo-induced

in a reusable fashion with ample scope. Second, the silica-based hybrid copper catalyst allowed for light-induced $\mathrm{C}-\mathrm{H}$ arylations of various heterocycles, featuring robust recyclability without significant loss of catalytic efficacy. Given the sustainable nature of photo-induced $\mathrm{C}-\mathrm{H}$ activation with reusable transition metal catalysts, we strongly believe that further exciting advances can be envisaged in
C-H arylation of imidazole-based heterocycles. $\mathbf{c}$ Robust hybrid copper catalysis for photo-induced $\mathrm{C}-\mathrm{H}$ arylation with cost-effective aryl bromides 40

this research arena, which will guide recyclable and environmentally sound methodologies for molecular assembly-line synthesis. These should require multidisciplinary collaborations, including the exploration of alternative metals [60], the engineering of innovative materials [61, 62], electrocatalysis [63-66], and asymmetric $\mathrm{C}-\mathrm{H}$ transformations [67, 68], among others. 
Fig. 9 Recyclability and metal leaching of the hybrid copper catalyst for photo-induced $\mathrm{C}-\mathrm{H}$ arylation

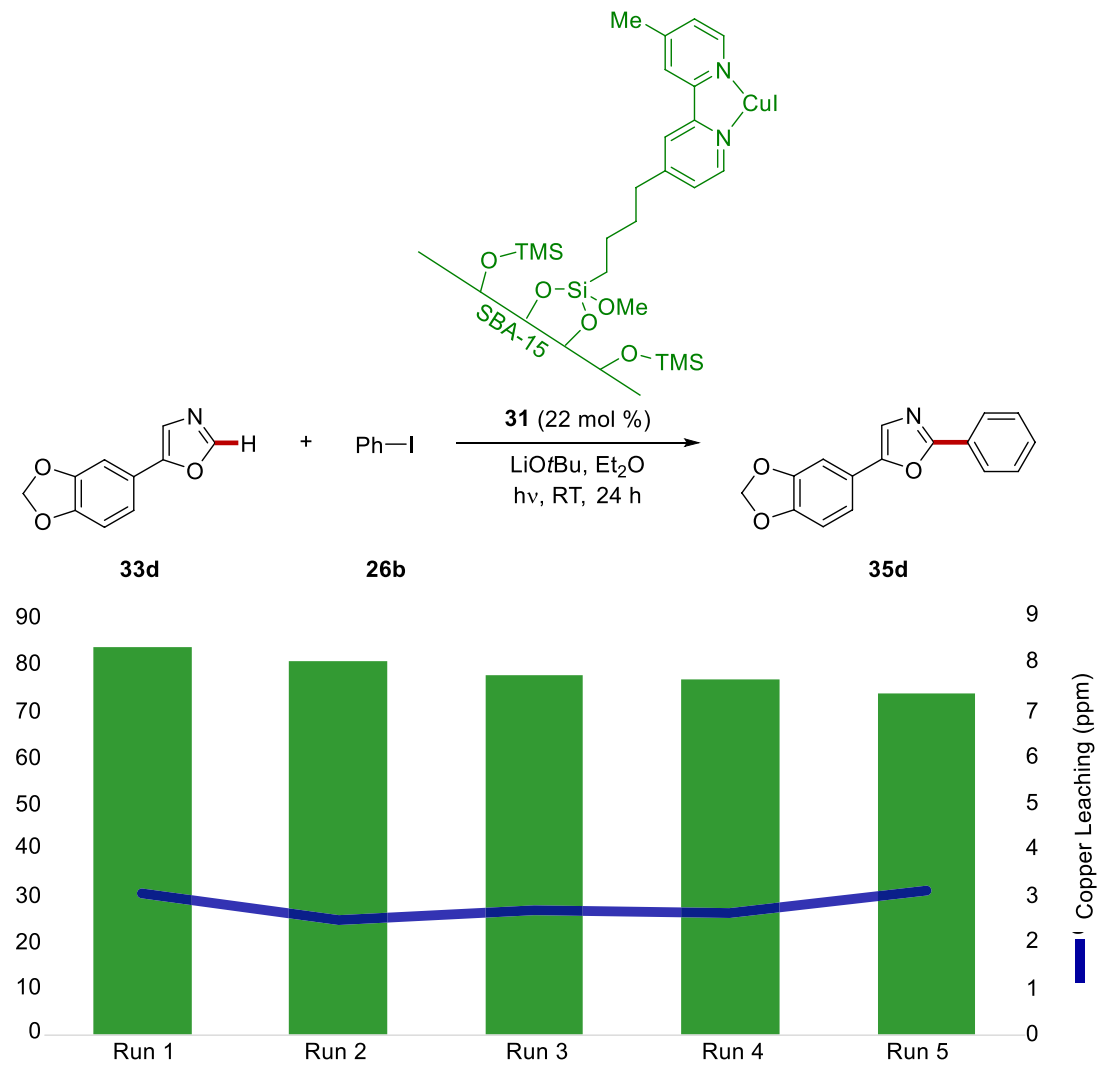

Acknowledgements Generous support from the Kwanjeong Educational Foundation (fellowship to I.C.) and the ERC Advanced Grant [101021358]/DFG Gottfried-Wilhelm-Leibniz-Preis (conferred on L.A.) is gratefully acknowledged. L.A. thanks Prof. Christian Jooss, Prof. Wolfgang Viöl, Dr. Loren B. Andreas, Dr. Volker Karius, and Dr. Johan G. Alauzun for their valuable contributions in material characterizations within fruitful collaborations.

Author contributions LA proposed the topic of the Account. IC, JS, and LA wrote the manuscript.

Funding Open Access funding enabled and organized by Projekt DEAL.

\section{Declarations}

Conflict of interest The authors declare no competing financial interests.

Open Access This article is licensed under a Creative Commons Attribution 4.0 International License, which permits use, sharing, adaptation, distribution and reproduction in any medium or format, as long as you give appropriate credit to the original author(s) and the source, provide a link to the Creative Commons licence, and indicate if changes were made. The images or other third party material in this article are included in the article's Creative Commons licence, unless indicated otherwise in a credit line to the material. If material is not included in the article's Creative Commons licence and your intended use is not permitted by statutory regulation or exceeds the permitted use, you will need to obtain permission directly from the copyright holder. To view a copy of this licence, visit http://creativecommons.org/licenses/by/4.0/.

\section{References}

1. Johansson Seechurn, C. C., Kitching, M. O., Colacot, T. J., \& Snieckus, V. (2012). Palladium-catalyzed cross-coupling: A historical contextual perspective to the 2010 Nobel Prize. Angewandte Chemie International Edition, 51(21), 5062-5085.

2. Biffis, A., Centomo, P., Del Zotto, A., \& Zecca, M. (2018). $\mathrm{Pd}$ metal catalysts for cross-couplings and related reactions in the 21st century: A critical review. Chemical Reviews, 118(4), 2249-2295.

3. Bergman, R. G. (2007). C-H activation. Nature, 446(7134), 391-393.

4. Rogge, T., Kaplaneris, N., Chatani, N., Kim, J., Chang, S., Punji, B., Schafer, L. L., Musaev, D. G., Wencel-Delord, J., Roberts, C. A., Sarpong, R., Wilson, Z. E., Brimble, M. A., Johansson, M. J., \& Ackermann, L. (2021). C-H activation. Nature Reviews Methods Primers, 1(1), 43.

5. Ackermann, L. (2007). Chelation-assisted arylation via C-H bond cleavage. Topics in Organometallic Chemistry, 24, 35-60.

6. Lorion, M. M., Maindan, K., Kapdi, A. R., \& Ackermann, L. (2017). Heteromultimetallic catalysis for sustainable organic syntheses. Chemical Society Reviews, 46(23), 7399-7420.

7. Dhawa, U., Kaplaneris, N., \& Ackermann, L. (2021). Green strategies for transition metal-catalyzed $\mathrm{C}-\mathrm{H}$ activation in molecular syntheses. Organic Chemistry Frontiers, 8(17), 4886-4913. 
8. Chen, D.Y.-K., \& Youn, S. W. (2012). C-H activation: A complementary tool in the total synthesis of complex natural products. Chemistry-A European Journal, 18(31), 9452-9474.

9. Segawa, Y., Maekawa, T., \& Itami, K. (2015). Synthesis of extended $\pi$-systems through $\mathrm{C}-\mathrm{H}$ activation. Angewandte Chemie International Edition, 54(1), 66-81.

10. Karimov, R. R., \& Hartwig, J. F. (2018). Transition-metal-catalyzed selective functionalization of $\mathrm{C}(\mathrm{sp} 3)-\mathrm{H}$ bonds in natural products. Angewandte Chemie International Edition, 57(16), 4234-4241.

11. Guillemard, L., Kaplaneris, N., Ackermann, L., \& Johansson, M. J. (2021). Late-stage C-H functionalization offers new opportunities in drug discovery. Nature Reviews Chemistry, 5(8), 522-545.

12. Osawa, M., Nagai, H., \& Akita, M. (2007). Photo-activation of Pdcatalyzed Sonogashira coupling using a Ru/bipyridine complex as energy transfer agent. Dalton Transactions. https://doi.org/10. 1039/b618007h

13. Uygur, M., \& García Mancheño, O. (2019). Visible light-mediated organophotocatalyzed $\mathrm{C}-\mathrm{H}$ bond functionalization reactions. Organic \& Biomolecular Chemistry, 17(22), 5475-5489.

14. Guillemard, L., \& Wencel-Delord, J. (2020). When metal-catalyzed $\mathrm{C}-\mathrm{H}$ functionalization meets visible-light photocatalysis. Beilstein Journal of Organic Chemistry, 16, 1754-1804.

15. Struwe, J., Korvorapun, K., Zangarelli, A., \& Ackermann, L. (2021). Photo-induced ruthenium-catalyzed C-H benzylations and allylations at room temperature. Chemistry-A European Journal. https://doi.org/10.1002/chem.202103077

16. Gandeepan, P., Koeller, J., Korvorapun, K., Mohr, J., \& Ackermann, L. (2019). Visible-light-enabled ruthenium-catalyzed meta-C-H alkylation at room temperature. Angewandte Chemie International Edition, 58(29), 9820-9825.

17. Korvorapun, K., Struwe, J., Kuniyil, R., Zangarelli, A., Casnati, A., Waeterschoot, M., \& Ackermann, L. (2020). Photoinduced ruthenium-catalyzed $\mathrm{C}-\mathrm{H}$ arylations at ambient temperature. Angewandte Chemie International Edition, 59(41), 18103-18109.

18. Sagadevan, A., \& Greaney, M. F. (2019). meta-Selective C-H activation of arenes at room temperature using visible light: Dualfunction ruthenium catalysis. Angewandte Chemie International Edition, 58(29), 9826-9830.

19. Sagadevan, A., Charitou, A., Wang, F., Ivanova, M., Vuagnat, M., \& Greaney, M. F. (2020). Ortho C-H arylation of arenes at room temperature using visible light ruthenium $\mathrm{C}-\mathrm{H}$ activation. Chemical Science, 11(17), 4439-4443.

20. Liu, W., \& Ackermann, L. (2016). Manganese-catalyzed C-H activation. ACS Catalysis, 6(6), 3743-3752.

21. Moselage, M., Li, J., \& Ackermann, L. (2016). Cobalt-catalyzed C-H activation. ACS Catalysis, 6(2), 498-525.

22. Gandeepan, P., Müller, T., Zell, D., Cera, G., Warratz, S., \& Ackermann, L. (2019). 3d Transition metals for C-H activation. Chemical Reviews, 119(4), 2192-2452.

23. Son, J. (2021). Sustainable manganese catalysis for late-stage C-H functionalization of bioactive structural motifs. Beilstein Journal of Organic Chemistry, 17, 1733-1751.

24. Yang, F., Koeller, J., \& Ackermann, L. (2016). Photoinduced copper-catalyzed $\mathrm{C}-\mathrm{H}$ arylation at room temperature. Angewandte Chemie International Edition, 55(15), 4759-4762.

25. Gandeepan, P., Mo, J., \& Ackermann, L. (2017). Photo-induced copper-catalyzed C-H chalcogenation of azoles at room temperature. Chemical Communications, 53(43), 5906-5909.

26. Kalsi, D., Dutta, S., Barsu, N., Rueping, M., \& Sundararaju, B. (2018). Room-temperature C-H bond functionalization by merging cobalt and photoredox catalysis. ACS Catalysis, 8(9), $8115-8120$.
27. Santoro, S., Kozhushkov, S. I., Ackermann, L., \& Vaccaro, L. (2016). Heterogeneous catalytic approaches in C-H activation reactions. Green Chemistry, 18(12), 3471-3493.

28. Yoo, C.-J., Rackl, D., Liu, W., Hoyt, C. B., Pimentel, B., Lively, R. P., Davies, H. M. L., \& Jones, C. W. (2018). An immobilizeddirhodium hollow-fiber flow reactor for scalable and sustainable $\mathrm{C}-\mathrm{H}$ functionalization in continuous flow. Angewandte Chemie International Edition, 57(34), 10923-10927.

29. Rackl, D., Yoo, C.-J., Jones, C. W., \& Davies, H. M. L. (2017). Synthesis of donor/acceptor-substituted diazo compounds in flow and their application in enantioselective dirhodium-catalyzed cyclopropanation and C-H functionalization. Organic Letters, 19(12), 3055-3058.

30. Kawamorita, S., Murakami, S. R., Iwai, T., \& Sawamura, M. (2013). Synthesis of primary and secondary alkylboronates through site-selective $\mathrm{C}(\mathrm{sp} 3)-\mathrm{H}$ activation with silica-supported monophosphine-Ir catalysts. Journal of the American Chemical Society, 135(8), 2947-2950.

31. Murakami, R., Tsunoda, K., Iwai, T., \& Sawamura, M. (2014). Stereoselective C-H borylations of cyclopropanes and cyclobutanes with silica-supported monophosphane-Ir catalysts. Chemistry-A European Journal, 20(41), 13127-13131.

32. Murakami, R., Iwai, T., \& Sawamura, M. (2016). Site-selective and stereoselective $\mathrm{C}(\mathrm{sp} 3)-\mathrm{H}$ borylation of alkyl side chains of 1,3-azoles with a silica-supported monophosphine-iridium catalyst. Synlett, 27(8), 1187-1192.

33. Ghosh, M., \& De Sarkar, S. (2018). meta- and para-Selective C-H functionalization using transient mediators and noncovalent templates. Asian Journal of Organic Chemistry, 7(7), 1236-1255.

34. Mihai, M. T., Genov, G. R., \& Phipps, R. J. (2018). Access to the meta position of arenes through transition metal catalysed $\mathrm{C}-\mathrm{H}$ bond functionalisation: A focus on metals other than palladium. Chemical Society Reviews, 47(1), 149-171.

35. Dey, A., Sinha, S. K., Achar, T. K., \& Maiti, D. (2019). Accessing remote meta- and para-C(sp2)-H bonds with covalently attached directing groups. Angewandte Chemie International Edition, 58(32), 10820-10843.

36. Ackermann, L., Hofmann, N., \& Vicente, R. (2011). Carboxylate-assisted ruthenium-catalyzed direct alkylations of ketimines. Organic Letters, 13(7), 1875-1877.

37. Korvorapun, K., Moselage, M., Struwe, J., Rogge, T., Messinis, A. M., \& Ackermann, L. (2020). Regiodivergent C-H and decarboxylative alkylation by ruthenium catalysis: Ortho versus meta position-selectivity. Angewandte Chemie International Edition, 59(42), 18795-18803.

38. Li, J., De Sarkar, S., \& Ackermann, L. (2016). meta- and paraSelective $\mathrm{C}-\mathrm{H}$ functionalization by $\mathrm{C}-\mathrm{H}$ activation. Topics in Organometallic Chemistry, 55, 217-257.

39. Leitch, J. A., \& Frost, C. G. (2017). Ruthenium-catalysed $\sigma$-activation for remote meta-selective $\mathrm{C}-\mathrm{H}$ functionalisation. Chemical Society Reviews, 46(23), 7145-7153.

40. Korvorapun, K., Samanta, R. C., Rogge, T., Ackermann, L. (2021). In Maiti, D., \& S. Guin (Eds.), Remote C-H Bond Functionalizations (pp. 137-167). Wiley-VCH

41. Korvorapun, K., Samanta, R. C., Rogge, T., \& Ackermann, L. (2021). Remote C-H functionalizations by ruthenium catalysis. Synthesis, 53(17), 2911-2946.

42. Korvorapun, K., Kaplaneris, N., Rogge, T., Warratz, S., Stückl, A. C., \& Ackermann, L. (2018). Sequential meta-/ortho-C-H functionalizations by one-pot ruthenium(II/III) catalysis. ACS Catalysis, 8(2), 886-892.

43. Fumagalli, F., Warratz, S., Zhang, S.-K., Rogge, T., Zhu, C., Stückl, A. C., \& Ackermann, L. (2018). Arene-ligand-free ruthenium(II/III) manifold for meta-C-H alkylation: Remote purine diversification. Chemistry-A European Journal, 24(16), 3984-3988. 
44. Korvorapun, K., Kuniyil, R., \& Ackermann, L. (2020). Late-stage diversification by selectivity switch in meta-C-H activation: Evidence for singlet stabilization. ACS Catalysis, 10(1), 435-440.

45. Choi, I., Müller, V., Wang, Y., Xue, K., Kuniyil, R., Andreas, L. B., Karius, V., Alauzun, J. G., \& Ackermann, L. (2020). Recyclable ruthenium catalyst for distal meta-C-H activation. ChemistryA European Journal, 26(66), 15290-15297.

46. Gandeepan, P., Kaplaneris, N., Santoro, S., Vaccaro, L., \& Ackermann, L. (2019). Biomass-derived solvents for sustainable transition metal-catalyzed C-H activation. ACS Sustainable Chemistry \& Engineering, 7(9), 8023-8040.

47. McCann, S. D., \& Stahl, S. S. (2015). Copper-catalyzed aerobic oxidations of organic molecules: Pathways for two-electron oxidation with a four-electron oxidant and a one-electron redox-active catalyst. Accounts of Chemical Research, 48(6), 1756-1766.

48. Pirnot, M. T., Wang, Y.-M., \& Buchwald, S. L. (2016). Copper hydride catalyzed hydroamination of alkenes and alkynes. Angewandte Chemie International Edition, 55(1), 48-57.

49. Zhu, X., \& Chiba, S. (2016). Copper-catalyzed oxidative carbonheteroatom bond formation: A recent update. Chemical Society Reviews, 45(16), 4504-4523.

50. Chen, X., Hao, X.-S., Goodhue, C. E., \& Yu, J.-Q. (2006). Cu(II)catalyzed functionalizations of aryl $\mathrm{C}-\mathrm{H}$ bonds using $\mathrm{O}_{2}$ as an oxidant. Journal of the American Chemical Society, 128(21), 6790-6791.

51. Díaz-Requejo, M. M., \& Pérez, P. J. (2008). Coinage metal catalyzed $\mathrm{C}-\mathrm{H}$ bond functionalization of hydrocarbons. Chemical Reviews, 108(8), 3379-3394.

52. Brasche, G., \& Buchwald, S. L. (2008). C-H functionalization/C$\mathrm{N}$ bond formation: Copper-catalyzed synthesis of benzimidazoles from amidines. Angewandte Chemie International Edition, 47(10), 1932-1934.

53. Wendlandt, A. E., Suess, A. M., \& Stahl, S. S. (2011). Coppercatalyzed aerobic oxidative C-H functionalizations: Trends and mechanistic insights. Angewandte Chemie International Edition, 50(47), 11062-11087.

54. Guo, X.-X., Gu, D.-W., Wu, Z., \& Zhang, W. (2015). Coppercatalyzed $\mathrm{C}-\mathrm{H}$ functionalization reactions: Efficient synthesis of heterocycles. Chemical Reviews, 115(3), 1622-1651.

55. Rao, W.-H., \& Shi, B.-F. (2016). Recent advances in coppermediated chelation-assisted functionalization of unactivated C-H bonds. Organic Chemistry Frontiers, 3(8), 1028-1047.
56. Daugulis, O. (2010). Palladium and copper catalysis in regioselective, intermolecular coupling of $\mathrm{C}-\mathrm{H}$ and $\mathrm{C}-\mathrm{Hal}$ bonds. Topics in Current Chemistry, 292, 57-84.

57. Yoshizumi, T., Tsurugi, H., Satoh, T., \& Miura, M. (2008). Copper-mediated direct arylation of benzoazoles with aryl iodides. Tetrahedron Letters, 49(10), 1598-1600.

58. Ackermann, L., Potukuchi, H. K., Landsberg, D., \& Vicente, R. (2008). Copper-catalyzed "click" reaction/direct arylation sequence: Modular syntheses of 1, 2, 3-triazoles. Organic Letters, 10(14), 3081-3084.

59. Choi, I., Müller, V., Lole, G., Köhler, R., Karius, V., Viöl, W., Jooss, C., \& Ackermann, L. (2020). Photoinduced heterogeneous $\mathrm{C}-\mathrm{H}$ arylation by a reusable hybrid copper catalyst. Chemistry- $A$ European Journal, 26(16), 3509-3514.

60. Choi, I., Shen, Z., Ronge, E., Karius, V., Jooss, C., \& Ackermann, L. (2021). Reusable manganese catalyst for site-selective pyridine C-H arylations and alkylations. Chemistry, 27(50), 12737-12741.

61. Newman, S. G., \& Jensen, K. F. (2013). The role of flow in green chemistry and engineering. Green Chemistry, 15(6), 1456-1472.

62. Swager, T. M. (2017). 50th anniversary perspective: Conducting/ semiconducting conjugated polymers. A personal perspective on the past and the future. Macromolecules, 50(13), 4867-4886.

63. Sauermann, N., Meyer, T. H., Qiu, Y., \& Ackermann, L. (2018). Electrocatalytic C-H activation. ACS Catalysis, 8(8), 7086-7103.

64. Ackermann, L. (2020). Metalla-electrocatalyzed C-H activation by earth-abundant $3 \mathrm{~d}$ metals and beyond. Accounts of Chemical Research, 53(1), 84-104.

65. Meyer, T. H., Choi, I., Tian, C., \& Ackermann, L. (2020). Powering the future: How can electrochemistry make a difference in organic synthesis? Chem, 6(10), 2484-2496.

66. Zhu, C., Ang, N. W. J., Meyer, T. H., Qiu, Y., \& Ackermann, L. (2021). Organic electrochemistry: Molecular syntheses with potential. ACS Central Science, 7(3), 415-431.

67. Loup, J., Dhawa, U., Pesciaioli, F., Wencel-Delord, J., \& Ackermann, L. (2019). Enantioselective C-H activation with earthabundant $3 \mathrm{~d}$ transition metals. Angewandte Chemie International Edition, 58(37), 12803-12818.

68. Dhawa, U., Tian, C., Wdowik, T., Oliveira, J. C. A., Hao, J., \& Ackermann, L. (2020). Enantioselective pallada-electrocatalyzed $\mathrm{C}-\mathrm{H}$ activation by transient directing groups: expedient access to helicenes. Angewandte Chemie International Edition, 59(32), 13451-13457. 